\title{
Soil organic matter quantity and quality shape microbial community compositions of subtropical broadleaved forests
}

\author{
JUNJUN DING, ${ }^{*}$ YUGUANG ZHANG,$\uparrow$ MENGMENG WANG, ${ }^{*}$ XIN SUN,$*$ JING CONG,$\uparrow$ \\ YE DENG, $\S$ HUI LU, $\uparrow$ TONG YUAN,§ JOY D. VAN NOSTRAND,§ DIQIANG LI, $\uparrow$ \\ JIZHONG ZHOU*§ $₫$ and YUNFENG YANG* \\ *State Key Joint Laboratory of Environment Simulation and Pollution Control, School of Environment, Tsinghua University, \\ Beijing 100084, China, †Institute of Forestry Ecology, Environment and Protection and the Key Laboratory of Forest Ecology \\ and Environment of State Forestry Administration, the Chinese Academy of Forestry, Beijing 100091, China, \$CAS Key \\ Laboratory of Environmental Biotechnology, Research Center for Eco-Environmental Sciences, Chinese Academy of Sciences, \\ Beijing 100085, China, §Institute for Environmental Genomics, Department of Microbiology and Plant Biology, University of \\ Oklahoma, Norman, OK 73019, USA, 『Earth Sciences Division, Lawrence Berkeley National Laboratory, Berkeley, CA 94720, \\ USA
}

\begin{abstract}
As two major forest types in the subtropics, broadleaved evergreen and broadleaved deciduous forests have long interested ecologists. However, little is known about their belowground ecosystems despite their ecological importance in driving biogeochemical cycling. Here, we used Illumina MiSeq sequencing targeting 16S rRNA gene and a microarray named GeoChip targeting functional genes to analyse microbial communities in broadleaved evergreen and deciduous forest soils of Shennongjia Mountain of Central China, a region known as 'The Oriental Botanic Garden' for its extraordinarily rich biodiversity. We observed higher plant diversity and relatively richer nutrients in the broadleaved evergreen forest than the deciduous forest. In odds to our expectation that plant communities shaped soil microbial communities, we found that soil organic matter quantity and quality, but not plant community parameters, were the best predictors of microbial communities. Actinobacteria, a copiotrophic phylum, was more abundant in the broadleaved evergreen forest, while Verrucomicrobia, an oligotrophic phylum, was more abundant in the broadleaved deciduous forest. The density of the correlation network of microbial OTUs was higher in the broadleaved deciduous forest but its modularity was smaller, reflecting lower resistance to environment changes. In addition, keystone OTUs of the broadleaved deciduous forest were mainly oligotrophic. Microbial functional genes associated with recalcitrant carbon degradation were also more abundant in the broadleaved deciduous forests, resulting in low accumulation of organic matters. Collectively, these findings revealed the important role of soil organic matter in shaping microbial taxonomic and functional traits.
\end{abstract}

Keywords: evergreen and deciduous forests, GeoChip, microbial community, molecular ecological network

Received 9 July 2015; revision received 5 September 2015; accepted 9 September 2015

Correspondence: Yunfeng Yang, Fax: +86 $010(+86)$

10 62785687; E-mail: yangyf@tsinghua.edu.cn

J.D. and Y.Z. contributed equally to this work.

\section{Introduction}

The broadleaved forests, with the highest detectable vegetation density (Shabanov et al. 2005), are among primary vegetation types of terrestrial environments. The broadleaved evergreen forest and broadleaved 
deciduous forests are major vegetation types in the subtropical climate zone (Kira 1991). Therefore, there have been a number of studies to compare plant distribution patterns, physiological characteristics, photosynthetic activity and nutrient dynamics between evergreen and deciduous plants (Williams-Linera 1997, 2000; Villar et al. 2006; Kröber et al. 2014). Evergreen plants appear to have an adaptive advantage in nutrient-poor habitats, owing to a higher nutrient-use efficiency than deciduous plants because of their longer leaf-lifespan (Givnish 2002). As a consequence, evergreen forests were known to accumulate more organic matter and have longer residence times of organic matter in the forest floor than deciduous forests in similar climatic zones (Vogt et al. 1986). The root mass and turnover were also higher in evergreen forests than deciduous forests.

To date, the majority of studies exploring the differences between evergreen and deciduous forests are plant-centric, for example plant survival, productivity and nutrient dynamics. Little attention has been paid to belowground microbial community, which plays an important role in driving biogeochemical processes (Falkowski et al. 2008). It was shown that soil respiration rate during the growing season was higher in the evergreen forest than that of the deciduous forest (Hibbard et al. 2005). It was also shown that different forest types were selected for different microbial community composition and activities (Li et al. 2014). To date, there are few in-depth, comprehensive investigations of the whole microbial community composition, despite several studies focusing on a subset of the microbial community (Yang et al. 2014a) or overall composition using coarse-resolution techniques such as PLFA or 16S rRNA gene RFLP technologies (Hackl et al. 2005; Yang et al. 2014a). Furthermore, no effort has been made to analyse microbial interaction, which might play an important role in dictating the flow of energy, material and information within a habitat (Montoya et al. 2006; Zhou et al. 2010, 2011).

Here, we used 16S rRNA gene-based sequencing to examine soil microbial community composition of natural broadleaved forests, and GeoChip 4.0 to examine their functional potentials. We also constructed microbial correlation network to conceptually examine microbial interactions with a random matrix theory (RMT)-based algorithm (Zhou et al. 2011; Deng et al. 2012). We postulate that soil microbial communities have been well adapted to the environments in natural forests. Given that plant community should have a strong effect on soil microbial community, we postulate that plant composition is a key mechanism in shaping microbial community. To test them, we collected soil samples from two adjacent, typical natural broadleaved evergreen forest and broadleaved deciduous forest in the Shennongjia national natural reserve (SNNR), which is located in the north-west of Hubei province, China. SNNR is one of the most biodiverse areas in China (Zhao et al. 2005) and a member of UNESCO's World Network of Biosphere Reserves.

\section{Methods and materials}

\section{Site and sampling}

The sampling site is located at Shennongiia National Nature Reserve (SNNR, $110^{\circ} 35^{\prime}-110^{\circ} 54^{\prime}$ E, $31^{\circ} 40^{\prime}-31^{\circ} 49^{\prime}$ $\mathrm{N}$ ) in the Shennongjia Mountains within the north-west Hubei province in Central China. This area is characterized by subtropical monsoon, with annual average air temperature of $7.2{ }^{\circ} \mathrm{C}$ and annual average precipitation of $1500 \mathrm{~mm}$ (Ma et al. 2008). The dominant species in the broadleaved deciduous forest is Quercus aliena var. acutiserrata of the Fagaceae family, and the dominant species in the broadleaved evergreen forest is Machilus calcieola of the Lauraceae family.

Soil samples were collected in August 2011. To guarantee the representativeness of soil samples in each forest type, a strip sampling method was used. Specifically, eight plots of typical vegetation in each forest with a size of $20 \times 20 \mathrm{~m}$ were selected, with an interval of at least $20 \mathrm{~m}$ in between. At each plot, ten topsoil cores of $1.5 \mathrm{~cm}$ diameter were taken at the depth of $0-10 \mathrm{~cm}$, mixed completely and sieved with 2-mm mesh to remove visible stones and roots. Soils were kept on ice during transportation to laboratory, divided into two subsamples and stored at either $-80{ }^{\circ} \mathrm{C}$ for DNA extraction or $4{ }^{\circ} \mathrm{C}$ for soil parameter measurements.

\section{Soil and vegetation parameters measurements}

In situ soil temperature was measured with a Hobo Temperature instrument at the depths of 5, 10 and $15 \mathrm{~cm}$. The other soil geochemical parameters were measured with soil samples in the laboratory as previously described (Ding et al. 2015), which included soil moisture, soil $\mathrm{pH}$, total soil organic carbon (SOC), total nitrogen, alkaline hydrolysis nitrogen, ammonium, nitrate, total phosphorus, rapidly available phosphorous, total sulphur, total potassium, dissolved organic carbon (DOC), labile organic carbon (LOC), $\delta^{13} \mathrm{C}, \delta^{15} \mathrm{~N}$, soil microbial biomass carbon and nitrogen. For plant communities, the trees $(>5 \mathrm{~cm}$ diameter at breast height), shrubs $(>1 \mathrm{~cm}$ diameter at breast height) and herbs were surveyed at each plot. The information about plant species, the number and canopy of each plant, the diameter of breast height and the height of each tree and shrub was collected. The Shannon-Weaver index $\left(\mathrm{H}^{\prime}\right)$ was used to calculate the plant diversity. 


\section{DNA extraction, purification and quantification}

DNA was extracted from $5 \mathrm{~g}$ well mixed, wet-weighted soil by freeze-grinding mechanical lysis as previously introduced (Zhou et al. 1996). Then, DNA was purified twice using $0.5 \%$ low melting point agarose gel before phenol-chloroform-butanol extraction. DNA quality was assessed by a Nanodrop (NanoDrop Technologies Inc., Wilmington, DE, USA), according to the ratios of $260 / 280 \mathrm{~nm}$ and $260 / 230 \mathrm{~nm}$.

\section{Illumina sequencing and data processing}

Two rounds of PCRs with a common primer pair targeting $\mathrm{v} 4$ region were performed before sequencing (Ding et al. 2015). The $2 \times 250 \mathrm{bp}$ paired-end sequencing of PCR amplicons targeting V4 hypervariable regions of the 16S rRNA gene was performed on a MiSeq platform (Illumina, San Diego, CA, USA) at the Institute for Environmental Genomics, University of Oklahoma. Raw sequences were separated to samples via sample-specific barcodes and with permission of up to one mismatch. UCLUST was used to classify the operational taxonomic units (OTUs) at the $97 \%$ similarity level (Edgar 2010), and singletons were removed. The taxonomic assignment was conducted by RDP classifier (Wang et al. 2007) with minimal $50 \%$ confidence estimates. Random resampling was performed with 19000 sequences per sample.

The Shannon-Weaver index was used to evaluate microbial diversity, and Simpson's evenness was used to evaluate microbial community evenness. Detrended correspondence analysis (DCA) was used to explore changes in overall microbial community composition. Partial Mantel tests based on the Bray-Curtis distances were performed to correlate microbial communities with environmental parameters. Principal components analysis (PCA) was used to collapse soil geochemical parameters into vectors. After examining scree plots, we retained the first principal component (PC1 of soil geochemical parameters), which explained $57.90 \%$ of the variation in soil geochemical parameters. Pearson correlation analyses were used to correlate the PC1 of soil geochemical parameters and microbial parameters. All of the analyses were conducted by functions in the VEGAN package (v.1.15-1) in R (v.3.0.1) (Oksanen et al. 2007).

\section{Network construction}

The correlation network based on random matrix theory was constructed from OTUs as previously described (Zhou et al. 2011; Deng et al. 2012). OTUs detected in less than six of eight replicates were removed to ensure reliable correlation networks. To explore the linkages between microbial community and environmental parameters, OTUs and environmental parameters detected in less than twelve of sixteen samples were removed to ensure reliable correlations. Based on the random matrix theory algorithm, transition of the nearest-neighbour spacing distribution of eigenvalues from GOE to Poisson distributions can serve as a threshold to remove random noise embedded in high-throughput sequencing data. A threshold of 0.92 was identified in our correlation networks.

Various indices were used to descript overall topological properties of different networks, including the average degree, average path distance, modularity, average clustering coefficient, geodesic efficiency, harmonic geodesic distance, density, transitivity and connectedness (Table S1, Supporting information). The CүTOSCAPE 2.8.3 software was used to visualize the network graphs (Cline et al. 2007). Each network was separated into modules to characterize the modularity property. Each network was separated into modules to characterize the modularity property. Based on the within-module connectivity ( $\mathrm{Zi}$, an index indicating how well a node connects to other nodes within the same module) and among-module connectivity $(\mathrm{Pi}$, an index indicating how well a node connects to different modules), the topological roles of different nodes were divided into four subcategories according to a previously described classification (Olesen et al. 2006): (i) network hubs are defined as nodes with $\mathrm{Zi}>2.5$ and $\mathrm{Pi}>0.62$; (ii) module hubs are defined as nodes with $\mathrm{Zi}>2.5$ and $\mathrm{Pi} \leq 0.62$; (iii) connectors are defined as nodes with $\mathrm{Zi} \leq 2.5$ and $\mathrm{Pi}>0.62$; and (iv) peripheral nodes are defined as nodes with $\mathrm{Zi} \leq 2.5$ and $\mathrm{Pi} \leq 0.62$.

\section{GeoChip hybridization and data processing}

Purified DNA was labelled with Cy3 dye and hybridized with GEOCHIP 4.0 as previously described (Yang et al. 2014b). After washing away unbound DNA, a NimbleGen MS 200 Microarray Scanner (Roche, Basel, Switzerland) was used to scan GeoChip microarrays with a 100\% laser power and 100\% photomultiplier tube. Poor-quality spots (signal-to-noise ratio of $<2.0$ ) were discarded without statistical analyses.

Signal intensities were processed using the analysis pipeline as previously described (Zhao et al. 2014; Yue et al. 2015). Then, preprocessed data were analysed by the following steps: (i) discarding genes detected in no more than two of eight samples from the same forest type; (ii) normalizing the signal intensity of each gene by dividing the signal intensity by the total intensity of each sample followed by multiplying by a constant; and (iii) doing natural logarithmic transformation. Partial Mantel tests were performed to correlate microbial 
functional composition with environmental parameters by functions in the VEGAN package based on the BrayCurtis distances between communities (v.1.15-1) in $\mathrm{R}$ (v.3.0.1) (Oksanen et al. 2007).

\section{Results}

\section{Plant and soil geochemical parameters}

The plant $\alpha$-diversity, calculated by the Shannon-Weaver index, was $42.27 \%$ higher $(P=0.009)$ in the broadleaved evergreen forest than in the broadleaved deciduous forest. A number of soil geochemical param- eters, including soil labile organic carbon, total nitrogen, alkaline hydrolysis nitrogen, rapid available phosphorus, total phosphorus, total sulphur, $\mathrm{pH}$ and temperature, were significantly $(P<0.050)$ higher by $386.51 \%$, $113.18 \%, 45.88 \%, 95.25 \%, 420.10 \%, 170.07 \%, 22.30 \%$, $21.57 \%$, respectively, in the broadleaved evergreen forest, suggestive of a nutrient-rich environment. In contrast, total potassium, $\mathrm{NH}_{4}^{+}-\mathrm{N}$ and moisture were significantly lower in the broadleaved evergreen forest by $52.57 \%, 37.76 \%, 25.78 \%$, respectively (Table 1 ). In addition, compositional dissimilarity (calculated by Bray-Curtis dissimilarity) of environmental parameters of broadleaved evergreen forest (0.249) was higher than

Table 1 Summary of environmental parameters with two-tailed $t$-tests and their relationships with microbial communities by partial Mantel tests

\begin{tabular}{|c|c|c|c|c|c|}
\hline & \multirow[b]{2}{*}{$\begin{array}{l}\text { Broadleaved } \\
\text { evergreen forest }\end{array}$} & \multirow[b]{2}{*}{$\begin{array}{l}\text { Broadleaved } \\
\text { deciduous forest }\end{array}$} & \multirow[b]{2}{*}{$\begin{array}{l}T \text {-test } \\
(P \text { value })\end{array}$} & \multicolumn{2}{|c|}{ Partial Mantel test: $r_{M}(P)$} \\
\hline & & & & With OTUs & $\begin{array}{l}\text { With } \\
\text { functional } \\
\text { genes }\end{array}$ \\
\hline \multicolumn{6}{|l|}{ Microbial parameters } \\
\hline Microbial diversity & $8.14 \pm 0.27$ & $7.72 \pm 0.15$ & 0.004 & - & - \\
\hline Microbial evenness & $0.10 \pm 0.05$ & $0.04 \pm 0.02$ & 0.004 & & \\
\hline Soil microbial biomass carbon $(\mathrm{mg} / \mathrm{kg})$ & $815.42 \pm 255.67$ & $703.17 \pm 69.95$ & 0.262 & & \\
\hline Soil microbial biomass nitrogen $(\mathrm{mg} / \mathrm{kg})$ & $144.97 \pm 73.51$ & $85.48 \pm 11.91$ & 0.048 & & \\
\hline \multicolumn{6}{|l|}{ Plant parameters } \\
\hline Plant diversity & $3.13 \pm 0.29$ & $2.20 \pm 0.75$ & 0.009 & $-0.058(0.646)$ & $0.143(0.152)$ \\
\hline \multicolumn{6}{|l|}{ Soil biogeochemical parameters } \\
\hline Soil organic carbon $(\mathrm{mg} / \mathrm{kg})$ & $52579.92 \pm 28875.78$ & $30544.79 \pm 4083.96$ & 0.058 & $0.327(\mathbf{0 . 0 2 4})$ & $-0.008(0.484)$ \\
\hline Labile organic carbon $(\mathrm{mg} / \mathrm{kg})$ & $7965.32 \pm 4197.63$ & $1637.22 \pm 660.18$ & 0.002 & $0.356(\mathbf{0 . 0 2 0})$ & $0.003(0.459)$ \\
\hline Dissolved organic carbon (mg/kg) & $248.63 \pm 155.46$ & $135.47 \pm 39.51$ & 0.071 & $-0.199(0.934)$ & $0.561(\mathbf{0 . 0 0 1})$ \\
\hline Total nitrogen $(\mathrm{mg} / \mathrm{kg})$ & $4143.75 \pm 1795.61$ & $1943.75 \pm 367.65$ & 0.008 & $0.425(\mathbf{0 . 0 0 4})$ & $-0.084(0.697)$ \\
\hline Alkaline hydrolysis nitrogen $(\mathrm{mg} / \mathrm{kg})$ & $286.19 \pm 95.92$ & $196.18 \pm 43.27$ & 0.040 & $0.160(0.130)$ & $0.010(0.424)$ \\
\hline $\mathrm{NH}_{4}^{+}-\mathrm{N}(\mathrm{mg} / \mathrm{kg})$ & $11.95 \pm 2.30$ & $19.20 \pm 4.70$ & 0.004 & $0.153(0.154)$ & $-0.062(0.613)$ \\
\hline $\mathrm{NO}_{3}^{-}-\mathrm{N}(\mathrm{mg} / \mathrm{kg})$ & $9.02 \pm 5.42$ & $6.47 \pm 7.26$ & 0.438 & $0.168(0.112)$ & $-0.158(0.847)$ \\
\hline$\delta^{13} \mathrm{C}(\%)$ & $-26.97 \pm 0.14$ & $-26.34 \pm 0.30$ & 0.001 & $0.224(0.098)$ & $0.137(0.183)$ \\
\hline$\delta^{15} \mathrm{~N}(\%)$ & $1.27 \pm 0.57$ & $3.07 \pm 0.79$ & 0.001 & $0.270(0.076)$ & $0.229(0.135)$ \\
\hline Rapidly available phosphorus (mg/kg) & $6.17 \pm 2.85$ & $3.16 \pm 0.36$ & 0.015 & $0.159(0.174)$ & $0.262(0.938)$ \\
\hline Total phosphorus $(\mathrm{mg} / \mathrm{kg})$ & $1201.43 \pm 1151.89$ & $231.00 \pm 41.93$ & 0.040 & $0.014(0.375)$ & $0.064(0.291)$ \\
\hline Total sulphur $(\mathrm{mg} / \mathrm{kg})$ & $587.52 \pm 314.71$ & $217.54 \pm 179.08$ & 0.017 & $0.072(0.259)$ & $-0.080(0.688)$ \\
\hline Total potassium $(\mathrm{mg} / \mathrm{kg})$ & $1789.17 \pm 769.04$ & $3772.32 \pm 684.37$ & 0.001 & $0.015(0.375)$ & $0.064(0.291)$ \\
\hline $\mathrm{pH}$ & $6.58 \pm 0.91$ & $5.38 \pm 0.52$ & 0.009 & $0.666(0.001)$ & $-0.237(0.975)$ \\
\hline Moisture (\%) & $37.46 \pm 6.52$ & $50.47 \pm 2.93$ & 0.001 & $-0.067(0.656)$ & $-0.157(0.827)$ \\
\hline $\begin{array}{l}\text { Soil temperature at the depth } \\
\text { of } 5 \mathrm{~cm}\left({ }^{\circ} \mathrm{C}\right)\end{array}$ & $20.23 \pm 0.51$ & $16.70 \pm 0.40$ & 0.001 & $-0.136(0.889)$ & $0.037(0.423)$ \\
\hline $\begin{array}{l}\text { Soil temperature at the depth } \\
\text { of } 10 \mathrm{~cm}\left({ }^{\circ} \mathrm{C}\right)\end{array}$ & $19.82 \pm 0.52$ & $16.31 \pm 0.44$ & 0.001 & $-0.106(0.837)$ & $0.035(0.432)$ \\
\hline $\begin{array}{l}\text { Soil temperature at the depth } \\
\text { of } 15 \mathrm{~cm}\left({ }^{\circ} \mathrm{C}\right)\end{array}$ & $19.60 \pm 0.52$ & $16.06 \pm 0.47$ & 0.001 & $-0.101(0.823)$ & $0.036(0.402)$ \\
\hline Altitude (m) & $1030.88 \pm 19.50$ & $1778.25 \pm 41.92$ & 0.001 & $-0.154(0.908)$ & $0.121(0.174)$ \\
\hline
\end{tabular}

$P$-value of $t$-test has been corrected by multiple testing with 5\% FDR (false discovery rate). The partial Mantel statistic $r_{\mathrm{M}}$ estimates the correlation between each environmental parameter with microbial communities at the taxonomic or functional gene level, while controlling for the effect of other environmental parameters. $P$-values were calculated using the distribution of the partial Mantel test statistics estimated from 9999 permutations. Bold $P$-values denote significance at the $P<0.050$ level. 
that of broadleaved deciduous forest (0.082), suggestive of a more heterogeneous environment that might be attributed to relatively richer nutrients.

\section{Soil microbial biomass and overall community composition}

Soil microbial biomass carbon and nitrogen representing microbial biomass were higher by $15.96 \%$ and $69.60 \%$, respectively, in the broadleaved evergreen forest than the broadleaved deciduous forest (Table 1). A total of 572206 good-quality sequences targeting the 16S rRNA gene were obtained from 16 soil samples by Illumina MiSeq sequencing, ranging from 19126 to 80166 reads per sample. A total of 55666 OTUs were then generated after resampling with 19000 sequences per sample. The OTU richness was marginally significantly higher $(P=0.063)$ in the broadleaved evergreen forest (8208) than that in the broadleaved deciduous forest (7466). Accordingly, significantly $(P=0.001)$ higher microbial $\alpha$ diversity $(5.44 \%)$ and evenness $(150.00 \%)$ were detected in the broadleaved evergreen forest. Detrended correspondence analysis (DCA) showed that soil samples of the broadleaved evergreen forest were clearly separated from those of the broadleaved deciduous forest (Fig. S1, Supporting information), which was further verified by nonparametric multivariate statistical tests of dissimilarity (adonis, anosim and MRPP, $P<0.010$ ).

A total of 48812 functional genes were detected by GeoChip, which were classified into 15 gene categories. In sharp contrast to the finding of fewer OTUs in the broadleaved deciduous forest, significantly $(P=0.011)$ more functional genes (40 960) were detected in the broadleaved deciduous forest than that (36 391) of the broadleaved evergreen forest, suggesting that functional genes were more heterogeneous in the broadleaved deciduous forest despite lower taxonomic diversity.

\section{The linkage between environmental parameters and microbial community}

Partial Mantel tests were used to identify environmental parameters linking to soil microbial community compositions. At the taxonomic level, microbial community was significantly correlated with parameters related to soil organic carbon quantity and quality, such as soil organic carbon, labile organic carbon, total nitrogen and $\mathrm{pH}(P<0.050)$ (Table 1). At the functional gene level, microbial community was significantly correlated with dissolved organic carbon $(P=0.001)$. In contrast, plant parameters showed no significant correlation with microbial community.

To calculate the independent contribution of these environmental parameters to microbial community variations, environmental parameters were partitioned into three groups (soil geochemical parameters, plant parameters and climatic parameters). The results of partial Mantel tests showed that soil geochemical parameters were significantly correlated with both microbial taxonomic and functional gene compositions $(P<0.010)$ (Table 2$)$. In addition, Pearson correlation analyses between the principal component (PC) of soil geochemical parameters and microbial parameters showed that PC1 of soil geochemical parameters, accounting for $57.90 \%$ of total variations, was positively correlated with microbial taxonomic diversity $(r=0.736, P=0.001)$, soil microbial biomass carbon (smbc) $(r=0.702, P=0.002)$ and soil microbial biomass nitrogen (smbn) $(r=0.879, P=0.001)$, verifying close linkages between soil geochemical parameters and microbial parameters (Fig. 1).

Table 2 The relationships of microbial communities to different groups of environmental parameters revealed by partial Mantel tests

\begin{tabular}{|c|c|c|c|c|c|c|}
\hline \multirow[b]{2}{*}{$\begin{array}{l}\text { In association with: controlling } \\
\text { for: microbial communities }\end{array}$} & \multicolumn{2}{|l|}{ Soil $^{*}$} & \multicolumn{2}{|l|}{ Plant $^{\dagger}$} & \multicolumn{2}{|l|}{ Climate $^{\star}$} \\
\hline & $\begin{array}{l}\text { Plant } \\
r_{\mathrm{M}}(P)\end{array}$ & $\begin{array}{l}\text { Climate } \\
r_{M}(P)\end{array}$ & $\begin{array}{l}\text { Soil } \\
r_{\mathrm{M}}(P)\end{array}$ & $\begin{array}{l}\text { Climate } \\
r_{M}(P)\end{array}$ & $\begin{array}{l}\text { Soil } \\
r_{\mathrm{M}}(P)\end{array}$ & $\begin{array}{l}\text { Plant } \\
r_{\mathrm{M}}(P)\end{array}$ \\
\hline OTUs & $0.623(\mathbf{0 . 0 0 1})$ & $0.581(\mathbf{0 . 0 0 1})$ & $0.227(0.095)$ & $0.155(0.182)$ & 0.318 (0.004) & $0.382(\mathbf{0 . 0 0 3 )}$ \\
\hline Functional genes & $0.419(\mathbf{0 . 0 0 7})$ & $0.423(\mathbf{0 . 0 0 6})$ & $-0.154(0.801)$ & $-0.127(0.726)$ & $-0.111(0.864)$ & $0.029(0.358)$ \\
\hline
\end{tabular}

The partial Mantel statistic $r_{\mathrm{M}}$ estimates the correlation between environmental parameters with microbial communities at the taxonomic or functional gene level, while controlling for the effect of other environmental parameters. $P$-values were calculated using the distribution of the partial Mantel test statistics estimated from 9999 permutations. Bold $P$-values denote significance at the $P<0.050$ level.

*Soil parameters include dissolved organic carbon, alkaline hydrolysis nitrogen, $\delta^{13} \mathrm{C}, \delta^{15} \mathrm{~N}$, soil $\mathrm{pH}$, total phosphorus, which were selected by the BIO-ENV procedure.

†Plant parameter is the plant community composition comprised of the cover-abundance value (the product of mean cover-abundance and frequency) of each species at every site.

*Climate parameters include soil temperature and moisture. 

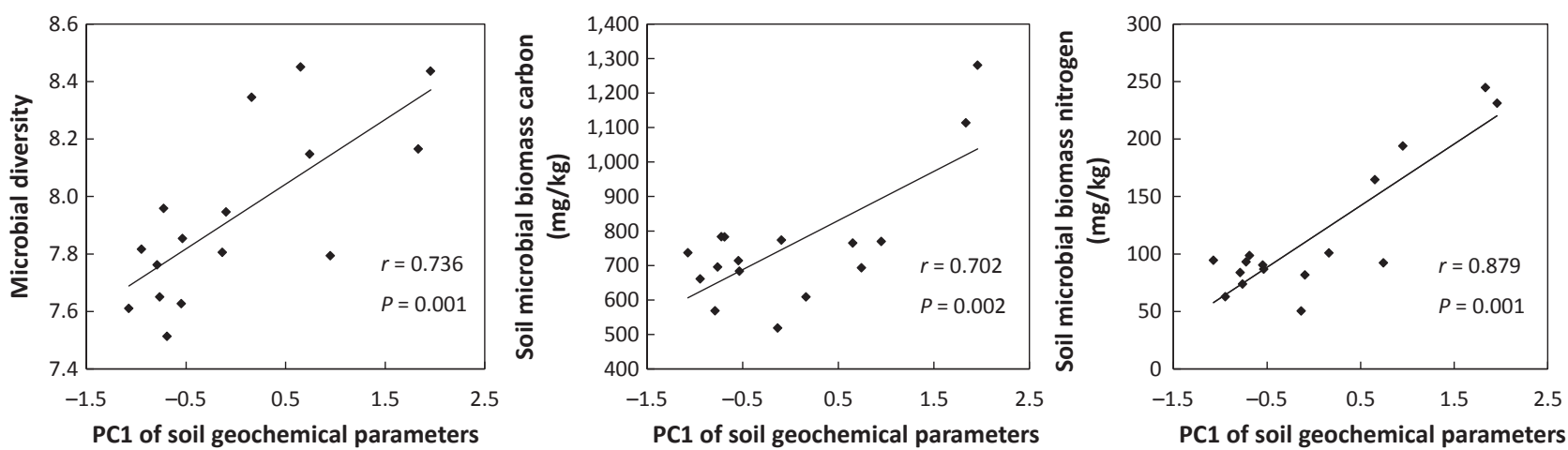

Fig. 1 Correlations between principal component (PC1) of soil geochemical parameters and microbial diversity, and microbial biomass indicated by soil microbial biomass carbon and soil microbial biomass nitrogen.

\section{Microbial communities at the taxonomic level}

All the detected OTUs were classified into 24 bacterial phyla. The abundant phyla accounting for more than $1 \%$ of the total communities were Proteobacteria (40.97\%), Acidobacteria (17.13\%), Verrucomicrobia $(13.22 \%)$, Actinobacteria (10.22\%), Planctomycetes $(4.75 \%)$, Bacteroidetes (3.18\%) and Firmicutes (2.14\%). Among them, the relative abundance of Verrucomicrobia, an oligotrophic phylum (Barnard et al. 2013), was $83.27 \%$ higher $(P=0.006)$ in the broadleaved deciduous forest (Fig. 2), which was relatively poorer in organic carbon contents (Table 1). In contrast, the relative abundance of Actinobacteria, a copiotrophic phylum, was $35.37 \%$ higher $(P=0.084)$ in the broadleaved evergreen forest.

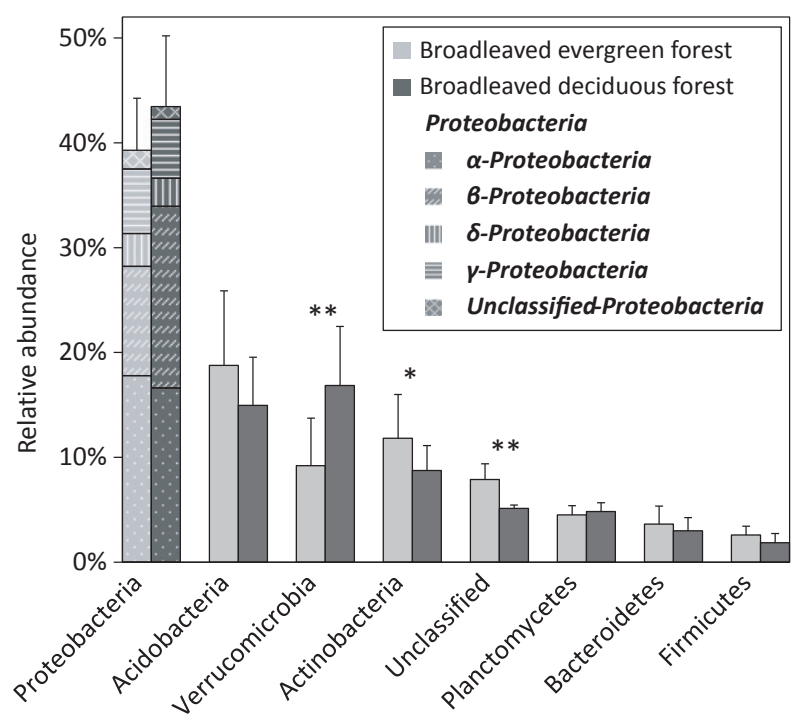

Fig. 2 Comparison of taxonomic distribution of major phyla between the broadleaved evergreen forest and the broadleaved deciduous forest. The asterisk (*) denotes significance at the $P<0.100$ level, and asterisk (**) denotes significance at the $P<0.050$ level.
The relative abundance of $\alpha-, \beta-, r$ - and $\delta$-Proteobacteria, Acidobacteria, Planctomycetes, Bacteroidetes and Firmicutes were similar between these two forests.

We compared the relative abundance of the unique OTUs defined as OTUs detected only in one forest. The relative abundance of unique Verrucomicrobia was $83.45 \%$ higher $(P=0.001)$ in the broadleaved deciduous forest, while the relative abundance of unique Actinobacteria was $128.20 \%$ higher $(P=0.030)$ in the broadleaved evergreen forest (Fig. S2).

\section{Correlation network analysis of microbial communities}

To explore possible interactions within microbial communities, we used a random matrix theory-based method (Zhou et al. 2011) to construct correlation networks from OTU data (See Method and Materials for details). The network of the broadleaved evergreen forest contained 683 nodes and the network of the broadleaved deciduous forest contained 745 nodes (Table S1) Both networks showed general features of biological networks, such as small world, scale free and modularity. The average degree in the network of the broadleaved deciduous forest, a key topological property to describe how well a node is connected with its neighbours, was about twice higher than that of the broadleaved evergreen forest, suggestive of more intensive microbial coupling. On the contrary, modularity, as a measurement of system resistance (Scheffer et al. 2012), was lower in the network of the broadleaved deciduous forest than that of the broadleaved evergreen forest (Table S1). The top 10 OTUs with the highest connectivity in broadleaved evergreen forest samples were assigned into three modules with relative fewer interactions (Fig. 3). In contrast, the top 10 OTUs in broadleaved deciduous forest samples were within one module and had more interactions. The top 10 OTUs of these two forests were both abundant, the relative abundance of which were almost 5 times higher than 


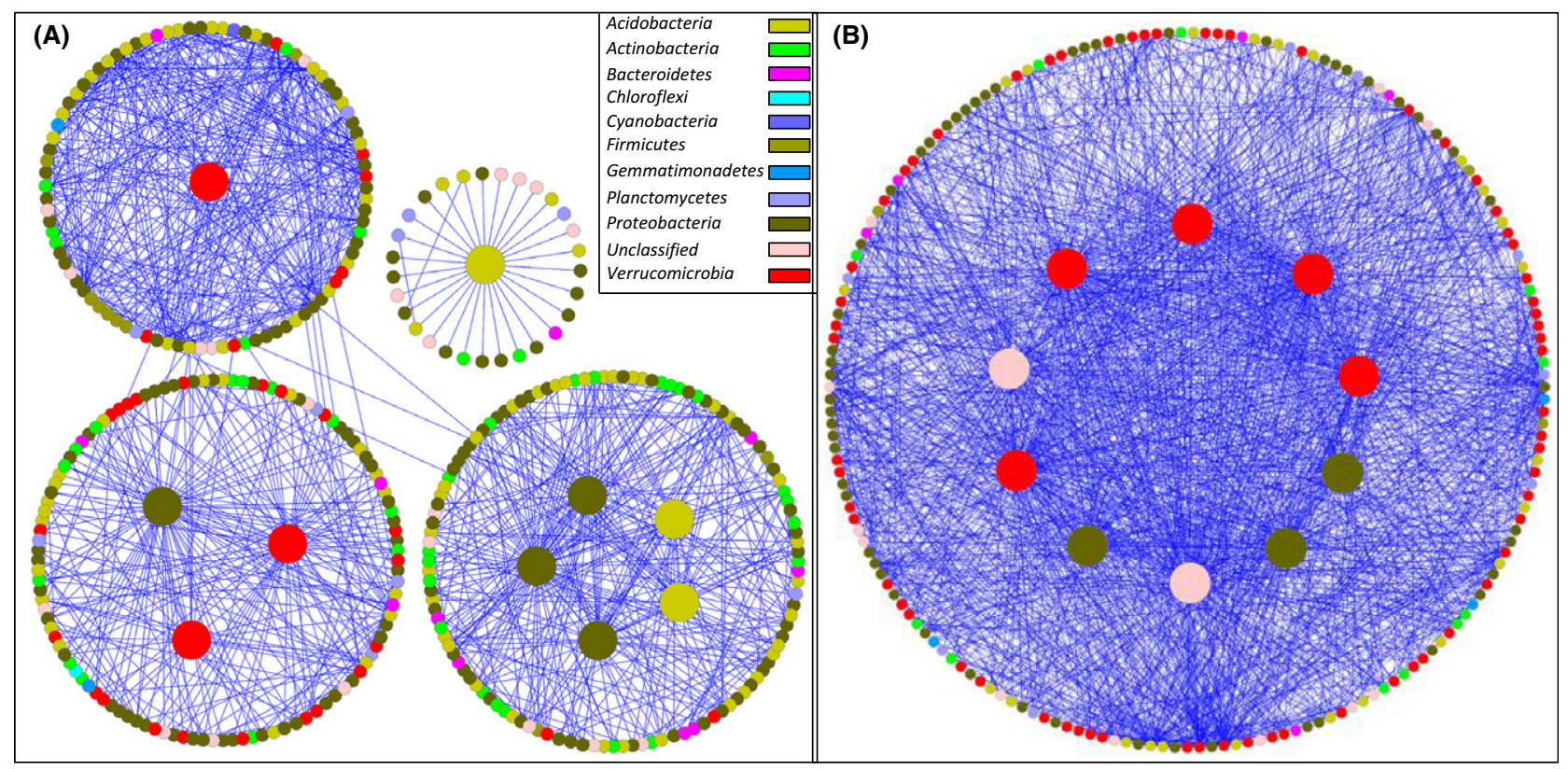

Fig. 3 Network interactions of key OTUs (the top ten OTUs with the highest connectivity) in (A) the broadleaved evergreen forest and (B) the broadleaved deciduous forest. Each node represents an OTU, and colours of the nodes indicate different phyla. The OTUs were separated into different modules, shown as circles, by the greedy modularity optimization method.

the average relative abundance of all the involved OTUs in the network.

Hubs and connectors are key nodes in structuring networks. A total of 16 hubs and 3 connectors were detected in the network of the broadleaved evergreen forest. The detected hubs were composed of seven Proteobacteria, six Acidobacteria, two Verrucomicrobia and one Actinobacteria. The three connectors were composed of two Proteobacteria and one Bacteroidates. In the network of the broadleaved deciduous forest, the 18 hubs were composed of seven Verrucomicrobia, four Acidobacteria, three Proteobacteria, two Actinobacteria and two unclassified OTUs (Fig. 4).

To explore the linkages between environmental parameters and microbial correlation networks, we treated environmental parameters as nodes and integrated them into the correlation networks. Among all of the environmental parameters, soil organic carbon, $\mathrm{pH}$ and rapid available phosphorus were hubs with the highest connectivity (Table S2).

\section{Microbial communities at the functional gene level}

Among all of the 15 detected gene categories, only genes associated with carbon cycle showed a significant $(P=0.022)$ difference between these two forests, with more carbon cycle genes in the broadleaved deciduous forest. Among them, genes associated with carbon fixation or starch degradation were similar between these two forests, while genes associated with more recalci-

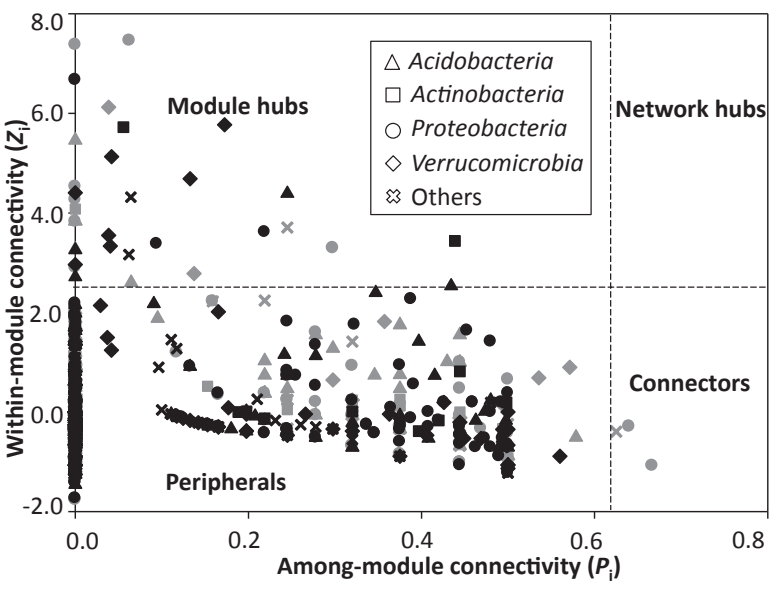

Fig. 4 The Z-P plot showing node categories according to within-module connectivity $(\mathrm{Zi})$ and among-module connectivity $(\mathrm{Pi})$. Each symbol represents an OTU in the broadleaved evergreen forest (grey) and the broadleaved deciduous forest (black). Different shapes of the symbol indicate different phyla.

trant carbon degradation, including polygalacturonase for pectin degradation, xylanase for hemicellulose degradation, cellobiase for cellulose degradation and endochitinase for chitin degradation, were significantly $(P<0.050)$ higher in the broadleaved deciduous forest (Fig. 5).

\section{Discussion}

The relationship between aboveground and belowground communities is important in understanding and 


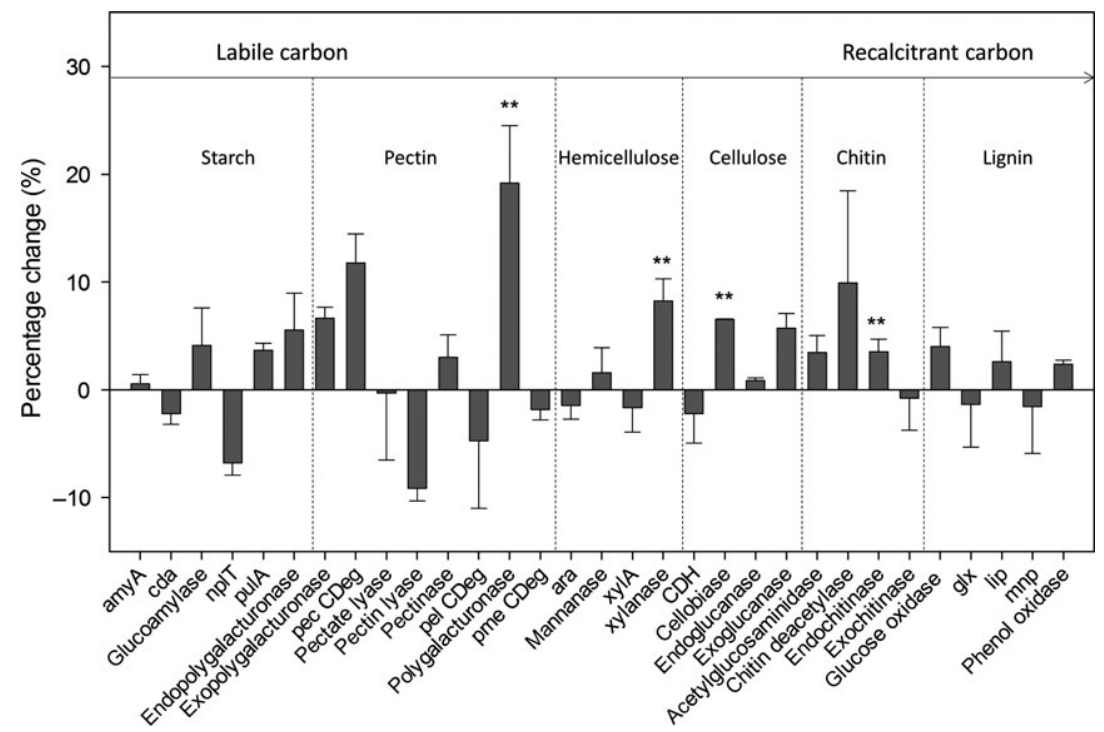

Fig. 5 The per cent change of the relative abundance of carbon degradation genes between two broadleaved forests, calculated as the mean value of replicates in the broadleaved deciduous forest divided by the mean value of replicates in the broadleaved evergreen forest minus one. The asterisk $(* *)$ denotes significance at the $P<0.050$ level. predicting ecosystem dynamics (Mitchell et al. 2010, 2012). Changes in the aboveground community can affect the belowground community through changes of soil $\mathrm{pH}$, litter quantity, litter quality and other nutrient factors (Zak et al. 2003; Högberg et al. 2007). Conversely, the belowground community can affect the aboveground community by driving a variety of soil biogeochemical processes (Wardle et al. 2004). Based on previous study showing that aboveground community was a major factor in shaping the belowground community (Spehn et al. 2000; Kowalchuk et al. 2002; Zak et al. 2003; Lamb et al. 2011), we expected that plant parameters were correlated with soil microbial community compositions. However, our study suggested that soil organic matter quantity and quality were the best predictors of microbial community in broadleaved forests, which supported the concept that soil geochemical parameters served as a bridge to link the aboveground community with the belowground community (Rasche et al. 2010). The aboveground community affects the belowground community by releasing a large proportion of accumulated carbon and nitrogen in the form of rhizodeposits and exudates and provides organic matter (Wardle 2002; Eisenhauer et al. 2010), which provides important nutrient sources for soil micro-organisms (Buckley \& Schmidt 2002; Rasche et al. 2010).

Previous studies focusing on the comparison between evergreen and deciduous forests have indicated that evergreen forests had an adaptive advantage in nutrient-poor habitats, and would accumulate more organic matter in the forest floor than deciduous forests located in similar climatic zones (Vogt et al. 1986; Aerts 1995). The greater organic matter inputs occurred in the broadleaved evergreen forest to soil might explain the higher microbial taxonomic diversity detected in the broadleaved evergreen forest (Zhou et al. 2002). As different natural forest types selected for distinct soil microbial communities (Hackl et al. 2005; Li et al. 2014), we found that the broadleaved evergreen forest soil contained more Actinobacteria (Fig. 2), known as copiotrophic bacteria preferentially living in abundant resources (Ramirez et al. 2012). In contrast, broadleaved deciduous forest soil contained more Verrucomicrobia, known as oligotrophic bacteria preferentially surviving in conditions with low nutrient availability (Barnard et al. 2013). In addition, the network analysis showed that more copiotrophic hubs were detected in the broadleaved evergreen forest, while more oligotrophic hubs were detected in the broadleaved deciduous forest (Fig. 4). Although general classification of oligotrophic and copiotrophic taxa was clearly oversimplifications of large variations in ecological attributes and microbial lifestyles, our results detected community-level copiotroph-oligotroph shifts and were consistent with the finding that soil organic matter quantity and quality could be used to predict community shift.

Correlation network analyses could provide important details of community assembly rules and represent mathematical interaction among different populations that regulate ecological processes (Fuhrman 2009). The higher average degree and shorter path length of the broadleaved deciduous forest network (Table S1) unveiled a possibility that microbial interaction was more intensive. Network theory suggests that tightly connected communities should be more susceptible to disturbance (Montoya et al. 2006; Saavedra et al. 2011); hence, the shorter path length in broadleaved deciduous forest network could increase the response rate of perturbations, as previously suggested (Barabasi \& Oltvai 2004). The more susceptible community structure of 
broadleaved deciduous forest was also reflected in the lower evenness (Table 1) of microbial community, which showed positive correlation with community stability in a previous work (Mikkelson et al. 2011). In addition, as modularity could serve as an indicator of system resistance by compartmentalizing social-ecological systems (Satti et al. 2003; Carpenter et al. 2012), lower modularity of the broadleaved deciduous forest network (Table S1) was suggestive of lower system resistance to changes, which might be explained by habitat-filtering processes in the broadleaved deciduous forest rendering the community much more homogeneous (Cornwell et al. 2006).

A recent study showed that taxonomical diversity was well aligned with functional diversity in US tallgrass prairie soils, which was ascribed to low degree of functional redundancy as changes in taxonomic traits were associated with those in functional traits (Fierer et al. 2013). In contrast, such linkage was absent at our study sites. Functional redundancy is considered as a fundamental property of microbial communities, which plays an essential role in microbial responses to environmental perturbation (Comte et al. 2013). However, the assessment of functional redundancy is complicated, as it can be assessed at the community or individual level, and potentially involves many different niche dimensions (Loreau 2004). Furthermore, functional redundancy of a certain populations under one set of environment might disappear under different environments (Allison \& Martiny 2008). To date, neither functional redundancy is well defined, nor experimentation to address it is widely accepted.

The quantity and quality of available carbon and nitrogen are important in regulating soil microbial functional processes (Högberg et al. 2007). The lower decomposition rates from poorer quality foliage input in litter fall and higher fine root mass addition were the possible explanations for the greater quantity of organic matter accumulation in evergreen forests (Vogt et al. 1986). Consistently, our GeoChip analysis showed that genes involved in recalcitrant carbon degradation were less abundant in the broadleaved evergreen forest (Fig. 5). This result also explained a previous observation that carbon utilization in the broadleaved deciduous forest was shifted to recalcitrant carbon substrate, as a response to lower level of labile organic carbon (Møller et al. 1999). The shift might be ascribed to the survival pressure, as microbes require sufficient quantities of nutrients to maintain their lives (Bray \& Gorham 1964). The consistency between the abundance of carbon degradation genes and organic carbon contents in soil suggested that abundance of carbon degradation genes could serve as an indicator of soil environment, which was in line with several recent studies (Morales et al. 2010; Liu et al. 2015).
In conclusion, here we report a survey of soil microbial communities in natural broadleaved forests. We found numerous evidences to link microbial community composition with soil organic matter quantity and quality, suggesting that microbial taxonomic and functional traits could be predicted by soil organic matter data. This study represents a step forward in elucidating association between different forest types and microbial communities, and suggests that microbial community is sensitive to potential dynamics of the natural forest ecosystems.

\section{Acknowledgements}

This research was supported by grants to Yuguang Zhang from the public welfare project of the National Scientific Research Institution (CAFRIFEEP201101), to Yunfeng Yang from the National Key Basic Research Programme of China (2013CB956601), Major Science and Technology Programme for Water Pollution Control and Treatment (2013ZX07315-001-03), the Strategic Priority Research Programme of the Chinese Academy of Sciences (XDB15010102), National High Technology Research and Development Programme of China (2012AA061401) and National Science Foundation of China (41471202 \& 41171201), to Ye Deng from State Key Laboratory of Forest and Soil Ecology (Grant No. LFSE2014-02) and the Strategic Priority Research Programme of the Chinese Academy of Sciences (Grant XDB15010302), and to Jizhong Zhou from the US National Science Foundation (EF-1065844).

\section{References}

Aerts R (1995) The advantages of being evergreen. Trends in Ecology \& Evolution, 10, 402-407.

Allison SD, Martiny JB (2008) Resistance, resilience, and redundancy in microbial communities. Proceedings of the National Academy of Sciences, 105, 11512-11519.

Barabasi A-L, Oltvai ZN (2004) Network biology: understanding the cell's functional organization. Nature Reviews Genetics, 5, 101-113.

Barnard RL, Osborne CA, Firestone MK (2013) Responses of soil bacterial and fungal communities to extreme desiccation and rewetting. The ISME Journal, 7, 2229-2241.

Bray JR, Gorham E (1964) Litter production in forests of the world. Advances in Ecological Research, 2, 101-157.

Buckley DH, Schmidt TM (2002) Exploring the Biodiversity of Soil-a microbial Rain Forest. Biodiversity of Microbial Life. Wiley-Liss Inc, New York.

Carpenter SR, Arrow KJ, Barrett S et al. (2012) General resilience to cope with extreme events. Sustainability, 4, 3248-3259.

Cline MS, Smoot M, Cerami E et al. (2007) Integration of biological networks and gene expression data using Cytoscape. Nature protocols, 2, 2366-2382.

Comte J, Fauteux L, del GP (2013) Links between metabolic plasticity and functional redundancy in freshwater bacterioplankton communities. Frontiers in Microbiology, 4, 112.

Cornwell WK, Schwilk DW, Ackerly DD (2006) A trait-based test for habitat filtering: convex hull volume. Ecology, 87, 1465-1471. 
Deng Y, Jiang Y-H, Yang Y et al. (2012) Molecular ecological network analyses. BMC Bioinformatics, 13, 113.

Ding J, Zhang Y, Deng Y et al. (2015) Integrated metagenomics and network analysis of soil microbial community of the forest timberline. Scientific Reports, 5, 7994.

Edgar RC (2010) Search and clustering orders of magnitude faster than BLAST. Bioinformatics, 26, 2460-2461.

Eisenhauer N, Beßler H, Engels C et al. (2010) Plant diversity effects on soil microorganisms support the singular hypothesis. Ecology, 91, 485-496.

Falkowski PG, Fenchel T, Delong EF (2008) The microbial engines that drive Earth's biogeochemical cycles. Science, 320, 1034-1039.

Fierer N, Ladau J, Clemente JC et al. (2013) Reconstructing the microbial diversity and function of pre-agricultural tallgrass prairie soils in the United States. Science, 342, 621-624.

Fuhrman JA (2009) Microbial community structure and its functional implications. Nature, 459, 193-199.

Givnish TJ (2002) Adaptive significance of evergreen vs. deciduous leaves: solving the triple paradox. Silva Fennica, 36, 703-743.

Hackl E, Pfeffer M, Donat C, Bachmann G, Zechmeister-Boltenstern S (2005) Composition of the microbial communities in the mineral soil under different types of natural forest. Soil Biology and Biochemistry, 37, 661-671.

Hibbard K, Law B, Reichstein M, Sulzman J (2005) An analysis of soil respiration across northern hemisphere temperate ecosystems. Biogeochemistry, 73, 29-70.

Högberg MN, Högberg P, Myrold DD (2007) Is microbial community composition in boreal forest soils determined by $\mathrm{pH}$, C-to-N ratio, the trees, or all three? Oecologia, 150, 590-601.

Kira T (1991) Forest ecosystems of east and southeast Asia in a global perspective. Ecological Research, 6, 185-200.

Kowalchuk GA, Buma DS, de Boer W, Klinkhamer PGL, van Veen JA (2002) Effects of above-ground plant species composition and diversity on the diversity of soil-borne microorganisms. Antonie Van Leeuwenhoek, 81, 509-520.

Kröber W, Heklau H, Bruelheide H (2014) Leaf morphology of 40 evergreen and deciduous broadleaved subtropical tree species and relationships to functional ecophysiological traits. Plant Biology, 17, 373-383.

Lamb EG, Kennedy N, Siciliano SD (2011) Effects of plant species richness and evenness on soil microbial community diversity and function. Plant and Soil, 338, 483-495.

Li H, Ye D, Wang X et al. (2014) Soil bacterial communities of different natural forest types in Northeast China. Plant and Soil, 383, 203-216.

Liu S, Wang F, Xue K et al. (2015) The interactive effects of soil transplant into colder regions and cropping on soil microbiology and biogeochemistry. Environmental Microbiology, 17, 566-576.

Loreau M (2004) Does functional redundancy exist? Oikos, 104, 606-611.

Ma C, Zhu C, Zheng C et al. (2008) High-resolution geochemistry records of climate changes since late-glacial from Dajiuhu peat in Shennongiia Mountains, Central China. Chinese Science Bulletin, 53, 28-41.

Mikkelson GM, McGill BJ, Beaulieu S, Beukema PL (2011) Multiple links between species diversity and temporal stability in bird communities across North America. Evolutionary Ecology Research, 13, 361-372.
Mitchell RJ, Hester AJ, Campbell CD et al. (2010) Is vegetation composition or soil chemistry the best predictor of the soil microbial community? Plant and Soil, 333, 417-430.

Mitchell RJ, Hester AJ, Campbell CD et al. (2012) Explaining the variation in the soil microbial community: do vegetation composition and soil chemistry explain the same or different parts of the microbial variation? Plant and Soil, 351, 355-362.

Møller J, Miller M, Kjøller A (1999) Fungal-bacterial interaction on beech leaves: influence on decomposition and dissolved organic carbon quality. Soil Biology and Biochemistry, 31, 367-374.

Montoya JM, Pimm SL, Solé RV (2006) Ecological networks and their fragility. Nature, 442, 259-264.

Morales SE, Cosart T, Holben WE (2010) Bacterial gene abundances as indicators of greenhouse gas emission in soils. The ISME Journal, 4, 799-808.

Oksanen J, Kindt R, Legendre P et al. (2007) The vegan package. Community ecology package, 631-637.

Olesen JM, Bascompte J, Dupont YL, Jordano P (2006) The smallest of all worlds: pollination networks. Journal of Theoretical Biology, 240, 270-276.

Ramirez KS, Craine JM, Fierer N (2012) Consistent effects of nitrogen amendments on soil microbial communities and processes across biomes. Global Change Biology, 18, 19181927.

Rasche F, Knapp D, Kaiser C et al. (2010) Seasonality and resource availability control bacterial and archaeal communities in soils of a temperate beech forest. The ISME Journal, 5, 389-402.

Saavedra S, Stouffer DB, Uzzi B, Bascompte J (2011) Strong contributors to network persistence are the most vulnerable to extinction. Nature, 478, 233-235.

Satti P, Mazzarino MJ, Gobbi M et al. (2003) Soil N dynamics in relation to leaf litter quality and soil fertility in northwestern Patagonian forests. Journal of Ecology, 91, 173-181.

Scheffer M, Carpenter SR, Lenton TM et al. (2012) Anticipating critical transitions. Science, 338, 344-348.

Shabanov NV, Huang D, Yang W et al. (2005) Analysis and optimization of the MODIS leaf area index algorithm retrievals over broadleaf forests. IEEE Transactions on Geoscience and Remote Sensing, 43, 1855-1865.

Spehn EM, Joshi J, Schmid B, Alphei J, Körner C (2000) Plant diversity effects on soil heterotrophic activity in experimental grassland ecosystems. Plant and Soil, 224, 217-230.

Villar R, Robleto JR, De Jong Y, Poorter H (2006) Differences in construction costs and chemical composition between deciduous and evergreen woody species are small as compared to differences among families. Plant, Cell \& Environment, 29, 1629-1643.

Vogt KA, Grier CC, Vogt D (1986) Production, turnover, and nutrient dynamics of above-and belowground detritus of world forests. Advances in Ecological Research, 15, 303-377.

Wang Q, Garrity GM, Tiedje JM, Cole JR (2007) Naïve Bayesian Classifier for Rapid Assignment of rRNA Sequences into the New Bacterial Taxonomy. Applied and Environmental Microbiology, 73, 5261-5267.

Wardle DA (2002) Communities and Ecosystems: Linking the Aboveground and Belowground Components. Princeton Univ Press, Princeton, New Jersey.

Wardle DA, Bardgett RD, Klironomos JN et al. (2004) Ecological linkages between aboveground and belowground biota. Science, 304, 1629-1633. 
Williams-Linera G (1997) Phenology of deciduous and broadleaved-evergreen tree species in a Mexican tropical lower montane forest. Global Ecology and Biogeography Letters, 6, 115-127.

Williams-Linera G (2000) Leaf demography and leaf traits of temperate-deciduous and tropical evergreen-broadleaved trees in a Mexican montane cloud forest. Plant Ecology, 149, 233-244.

Yang J-K, Zhang J-J, Yu H-Y, Cheng J-W, Miao L-H (2014a) Community composition and cellulase activity of cellulolytic bacteria from forest soils planted with broad-leaved deciduous and evergreen trees. Applied Microbiology and Biotechnology, 98, 1449-1458.

Yang Y, Gao Y, Wang S et al. (2014b) The microbial gene diversity along an elevation gradient of the Tibetan grassland. The ISME Journal, 8, 430-440.

Yue H, Wang M, Wang S et al. (2015) The microbe-mediated mechanisms affecting topsoil carbon stock in Tibetan grasslands. The ISME Journal, 9, 2012-2020.

Zak DR, Holmes WE, White DC, Peacock AD, Tilman D (2003) Plant diversity, soil microbial communities, and ecosystem function: are there any links? Ecology, 84, 2042-2050.

Zhao CM, Chen WL, Tian ZQ, Xie ZQ (2005) Altitudinal pattern of plant species diversity in Shennongjia Mountains, Central China. Journal of Integrative Plant Biology, 47, 14311449.

Zhao M, Xue K, Wang F et al. (2014) Microbial mediation of biogeochemical cycles revealed by simulation of global changes with soil transplant and cropping. The ISME Journal, 8, 2045-2055.

Zhou J, Bruns MA, Tiedje JM (1996) DNA recovery from soils of diverse composition. Applied and Environment Microbiology, 62, 316-322.

Zhou J, Xia B, Treves DS et al. (2002) Spatial and resource factors influencing high microbial diversity in soil. Applied and Environmental Microbiology, 68, 326-334.

Zhou J, Deng Y, Luo F et al. (2010) Functional molecular ecological networks. MBio, 1, e00169-10.

Zhou J, Deng Y, Luo F, He Z, Yang Y (2011) Phylogenetic molecular ecological network of soil microbial communities in response to elevated $\mathrm{CO}_{2}$. MBio, 2, e00122-11.
Y.Y., Y.Z., J.Z. and D.L. designed the experiments. J.D. and Y.Y. wrote the main manuscript text. J.D., M.W., X.S. and Y.D. analysed the data. J.C., H.L., T.Y. and J.V.N. performed the experiments. All authors reviewed the manuscript.

\section{Data accessibility}

Microarray data are accessible in NCBI GEO database with Accession No. GSE58433. Sequencing data are accessible in NCBI SRA database with Accession No. SRA291043. The OTU table as well as the input and output files of the network analyses is accessible in Dryad database with doi:10.5061/dryad.8071s.

\section{Supporting information}

Additional supporting information may be found in the online version of this article.

Fig. S1 Detrended correspondence analysis (DCA) of microbial community based on Illumina MiSeq sequencing data.

Fig. S2 Comparison of taxonomic distribution of unique OTUs at the phylum level between the broadleaved evergreen forest and the broadleaved deciduous forest.

Table S1 Comparison of topological properties of correlation networks between the broadleaved evergreen forest and the broadleaved deciduous forest.

Table S2 Node attributes of the correlated environmental parameters in the network. 